\title{
Review of the Literature and Case Report of Surgical Treatment of a Neglected Dislocation of Hamate
}

\author{
Krishna Kumar1 ${ }^{*}$, Alaa Kawas ${ }^{1}$, Thomas Abraham ${ }^{1}$, Renata de Kesel ${ }^{2}$ \\ ${ }^{1}$ Department of Orthopaedics, Hamad Medical Corporation, Doha, Qatar \\ ${ }^{2}$ Department of Orthopaedics Az Sint Lucas, Ghent, Belgium \\ Email: ${ }^{*}$ kkortho@yahoo.co.uk, mkawas1@hmc.org.qa, orthothomas@gmail.com, renatadekesel@yahoo.com
}

Received 26 June 2014; revised 18 August 2014; accepted 1 September 2014

Copyright (C) 2014 by authors and Scientific Research Publishing Inc.

This work is licensed under the Creative Commons Attribution International License (CC BY). http://creativecommons.org/licenses/by/4.0/

(c) (i) Open Access

\begin{abstract}
Introduction: Hamate dislocation is an uncommon injury, and there are only 17 reported cases in the literature. Ten of them are isolated injuries, and in 7 cases the hamate dislocation is a part of other injuries of the hand. Hamate dislocation can be caused by both direct and indirect forces, or as a part of complex injury of the wrist and hand. Case Report: A case report of a 26-year-old man who presented with a machine injury to his hand with a volar hamate dislocation which was initially missed in the Emergency department as a volar lacerated wound of the hand and was subsequently discovered in the Orthopaedic clinic 6 weeks later. Conclusion: This is only the second report in literature of a neglected hamate dislocation being surgically treated and the 18th reported case of a hamate dislocation over the last 130 years. The direction of dislocation depends on the direction of force applied. Surgical treatment with fixation is optimal even for neglected cases. There was no incidence of avascular necrosis of hamate reported, reflecting the almost equal volar and dorsal blood supply of the hamate.
\end{abstract}

\section{Keywords}

Hamate, Dislocation, Neglected, Surgery

\section{Introduction}

The Hamate sits on the distal carpal row on the ulnar side of the wrist. It articulates with the fourth and fifth metacarpals, capitate and triquetrum. The proximal surface has a convex shape to allow for articulation with the

*Corresponding author.

How to cite this paper: Kumar, K., Kawas, A., Abraham, T. and de Kesel, R. (2014) Review of the Literature and Case Report of Surgical Treatment of a Neglected Dislocation of Hamate. Open Journal of Orthopedics, 4, 243-248.

http://dx.doi.org/10.4236/ojo.2014.49040 
proximal carpal bones. The hook of the hamate projects upwards and forms one of the boundaries of the Guyon's canal through which the ulnar nerve and artery run. Fractures of the hamate are uncommon and form about 5 percent of carpal bone injuries. Dislocations are exceedingly rare and very little is known about the optimal management of these.

\section{Case Presentation}

A 26-year-old man working in a factory presented to the Accident and Emergency Department with machine injury to the left hand. There was a deep $3 \mathrm{~cm}$ laceration on the volar side of the wrist and hand with partially exposed median nerve. X-Rays were done and were considered as normal by the treating doctors in the Emergency. The wound was explored under local anaesthesia in the Emergency and was irrigated and closed. No tendon or nerve injury was detected.

After 6 weeks, because of persisting pain and limitation of wrist motion, the patient presented to the Orthopaedic clinic for the first time where the X-Rays were repeated including oblique views of the hand and the hamate dislocation was discovered. By this time, the volar wound had completely healed. There was no ulnar nerve neuropraxia (Figures 1-3).

At a total of eight weeks past injury, an open reduction through dorsal transverse approach was done. A complete volar dislocation of the hamate was found. No residual ligaments or soft tissues were available for repair. However, reduction was achieved without much difficulty. The hamate was fixed with 3 K-Wires, and a POP slab was applied (Figure 4).

The K-Wires were left for a period of 8 weeks after which physiotherapy was started.

The final clinical evaluation was performed one year after the injury according to a modified Green and O’Brien scoring system. Modified Green O’Brien Scoring System consists of four subscales-Pain, functional status, range of motion and grip strength (each with five sub-items for a total possible score of 100) (Table 1).

- Our clinical outcome rated as good (Figure 5).

The average grip strength was reduced by about $50 \%$ ( $24.6 \mathrm{~kg}$ compared to $47 \mathrm{~kg}$ on the normal side).

The patient had mild pain in the affected wrist but could return to his previous occupation with a good functional outcome (Figure 6).

\section{Literature Review}

From the 17 reported cases of hamate dislocation, only 10 were isolated dislocations of the hamate; the remaining 7 cases were dislocation of the hamate associated with other carpal injuries, or as part of complex injury to the wrist and hand.

The first review of literature was conducted by Geist in 1939. The first reported case goes back to 1882 by Buchanan.

Arnaud [1] in 1987 reported a dorsal dislocation of the hamate bone, and was treated with open reduction and fixation with $2 \mathrm{~K}$-wires. The clinical outcome was good, although the X-ray showed residual instability with motion.

In 1901 two consecutive reports about hamate dislocation were published, but in both cases the hamate dislocation was part of a more complex injury.

Ebermayer [2] 1908 reported one isolated volar dislocation of the hamate bone caused by a stamp machine. The injury was compound, the patient refused excision of the hamate, and his outcome was rated as poor.

Murphy [3] 1915 reported another isolated hamate dislocation, discovered 3 months after the initial trauma, treated with excision of the hamate, but the outcome was not reported in his paper.

Geist [4] 1939 had a case of dorsal dislocation of the hamate discovered 18 days after trauma. Close reduction failed and open reduction was done followed by POP immobilization.

Geist [4] claimed that a combination of both direct and indirect forces as being responsible for his case report. His patient had had a fall from scaffold, and the exact trauma mechanism causing the dislocation is uncertain.

Duke [5] 1963 had an anterior dislocation of the hamate by a hockey player. Closed reduction was successful, and POP was applied for 4 weeks.

1974 Ferraro reported another isolated dorsal dislocation of the hamate, treated with excision of hamate with good clinical outcome. 


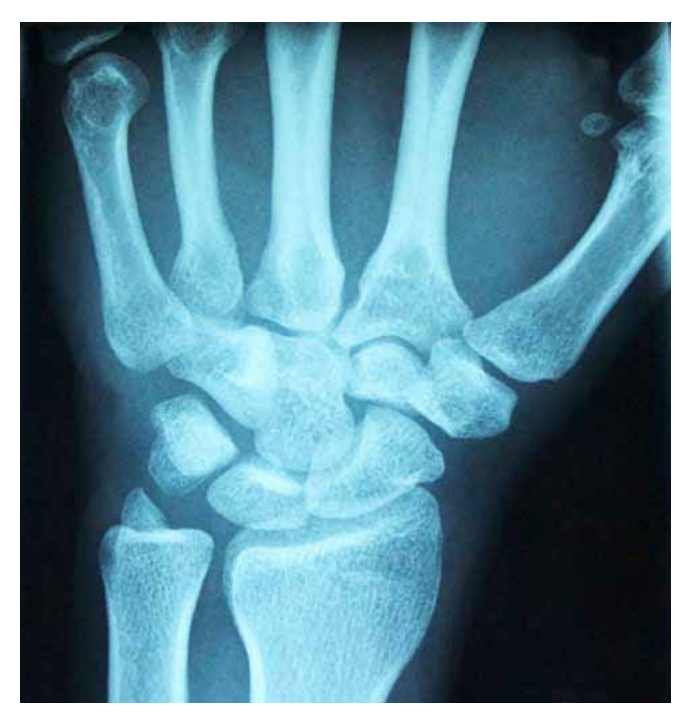

Figure 1. AP X-ray of hand shows obvious incongruity of hamate and fourth and fifth metacarpals.

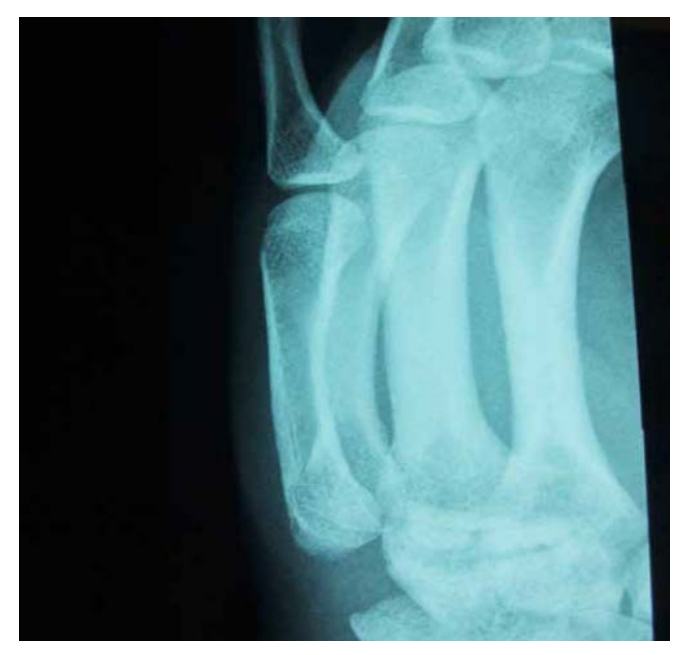

Figure 2. Lateral X-ray of Hand shows gap at base of fifth metacarpal.

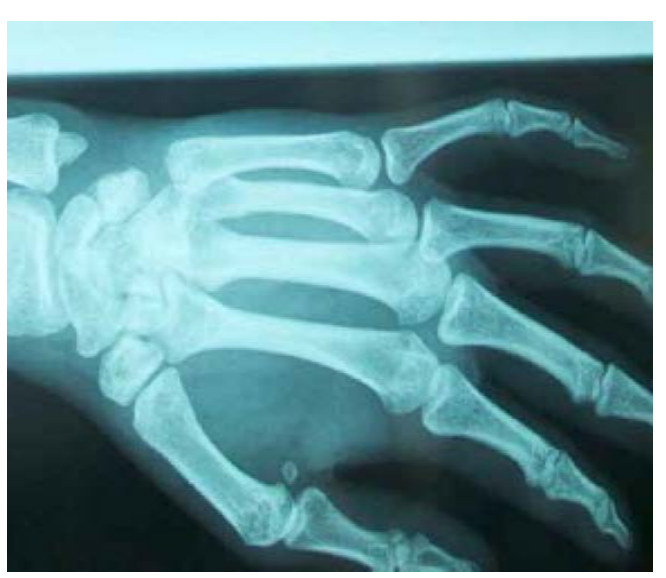

Figure 3. Oblique hand X-ray showing gap at the fifth metacarpal base-hamate articulation. 


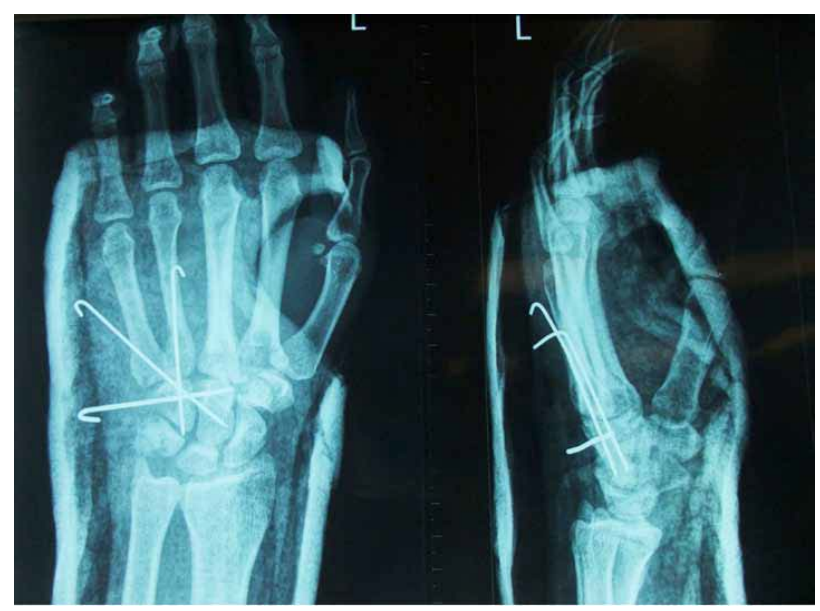

Figure 4. Post op X-ray showing hamate reduced in place and fixed by three $\mathrm{K}$ wires.
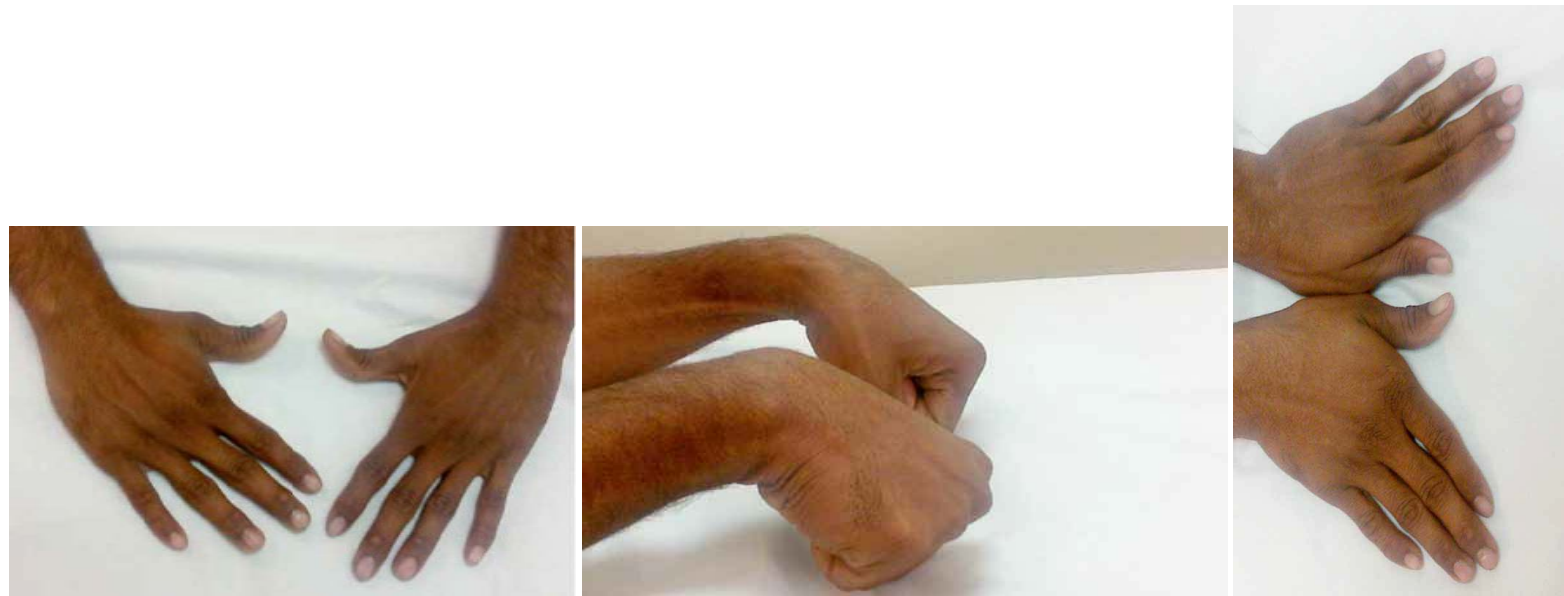

Figure 5. Post op Range of Movement at one year.
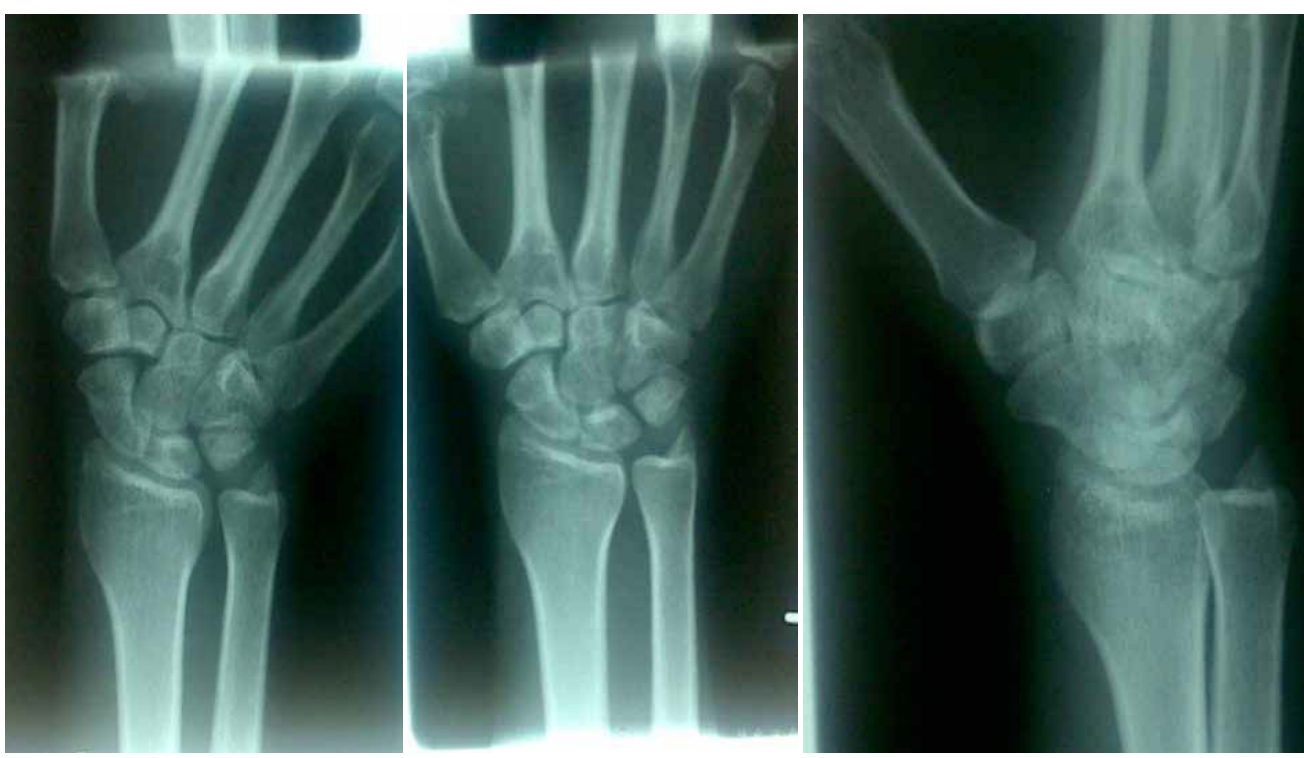

Figure 6. Check X-rays at one year shows hamate in position with no signs of arthritis or AVN. 
Table 1. Final ROM both wrists for our patient at one year after the injury compared to the normal side.

\begin{tabular}{ccc}
\hline & Dislocated side & Normal side \\
\hline Dorsiflexion & 66 & 95 \\
Palmar flexion & 70 & 80 \\
Radial deviation & 20 & 36 \\
Ulnar deviation & 30 & 47 \\
Pronation & 80 & 80 \\
Supination & 80 & 80 \\
\hline
\end{tabular}

Gainor [6] 1985 reported another hamate dislocation with associated injuries to the hand.

Gun [7] in 1985 had a case of volar hamate dislocation. Close reduction failed, and the patient underwent open reduction and K-wires fixation.

Zieren [8] (2000) reported a case of dorsal dislocation of the hamate, treated with close reduction and POP.

Johansson [9] 1926, Mathison [10] 1975, Matsumato [11] 2005 reported cases of hamate dislocations, associated with other injuries in the wrist and the hand.

The treatment ranged from excision of the hamate Johansson [8] to open reduction and K-wires fixation. "Mathison [9], Gainor [5], and Matsumoto [10]".

From the 17 cases, fall from height was the cause in four, machine injury in six cases, hit by a door or direct hit in three cases, motorcycle accident in two, car accident in one patient, and unclear cause in one patient.

Johansson [8] considered direct trauma is the main cause of this injury. In his patient, the dislocation was caused by a fall from height (indirect forces) and the explanation he provided was to compare the dislocation with the pressing of the kernel of cherry out of the fruit.

Matsumoto [10] considered axial loading as the cause of the injury, and supination or pronation of the wrist facilitates the transverse distribution of the forces.

\section{Discussion}

Almost equal number of dorsal and volar dislocations has been reported in literature. Dislocation can be either volar or dorsal according to the direction of force applied. A large number of hamate dislocations have occurred while working with heavy machinery and a high impact of power is needed to stamp the hamate out of its position.

Vascularity of hamate essentially arises from 3 sources:

Dorsal intercarpal arch.

Ulnar recurrent artery.

Ulnar artery.

Vessels enter through the non articular surface of hamate which include palmar (50\%), dorsal (30\% - 40\%) and medially through hook of hamate. This almost equal blood supply presumably accounts for the absence of any avascular necrosis occurring even in neglected cases.

Surgical treatment (ORIF) and fixation of hamate gives good results, even in neglected cases. Closed reduction, excision of the hamate, and open reduction with or without fixation have all been tried as treatment options, and the clinical outcome was in general good, regardless of the treatment method.

It was noted that grip strength was reduced in all cases reporting the clinical outcome of the patients. Because all reports have only short term follow up, no conclusion can be made, whether the weakness is permanent, or due to the trauma, treatment and immobilization.

In contrast, the motion of the wrist joint was good, and only minor limitation of motion was reported. This can be expected, especially in isolated hamate dislocation, as the hamate has insignificant contribution in the mechanism of movement of the wrist.

The Limitations of the study were the small numbers, which are to be expected from hamate dislocation, which are very rare. Moreover, we did not have a preop lateral view of wrist taken in the Emergency.

\section{Conclusion}

With a very limited number of patients, no definite recommendation can be given regarding the best treatment 
option, but we feel that urgent reduction, either closed or open, with K-wire fixation is an optimal method of treatment for both neglected and acute dislocations of the hamate, with a longer period of immobilization for the neglected cases.

\section{Clinical Message}

Hamate dislocations are exceedingly rare and can be easily missed. Oblique hand X-rays are helpful for diagnosis in suspected cases. Surgical management even in neglected cases gives good results and there was no evidence of avascular necrosis in these dislocations.

\section{References}

[1] Arnaud, J.P., Girou, P., Mabit, Ch. and Pecout, C. (1987) Luxation de l'os Cochu. A propos d'une observation avec revue de la literature. Annales de Chirurgie de la Main, 6, 222-224. http://dx.doi.org/10.1016/S0753-9053(87)80063-7

[2] Ebermayer, F. (1908) Ueber Isolierte Verletzung der Handwurzelknochen. Fortschr. A.d. Geb. D. Roentgenstrahlen, XII, 12, 1-22.

[3] Murphy, J.B. (1915) Dislocation of the Unciform Bone. Surgery Clinics, 4, 423.

[4] Geist, D.C. (1939) Dislocation of the Hamate Bone. Report of a Case. Journal Bone Joint Surgery, XXI, $215-217$.

[5] Duke, R. (1963) Dislocation of the Hamate Bone. Report of a Case. Journal Bone Joint Surgery. British, 45, 44.

[6] Gainor, B.J. (1985) Simultaneous Dislocation of the Hamate and Pisiform. A Case Report. Journal Hand Surgery. American, 10, 88-90. http://dx.doi.org/10.1016/S0363-5023(85)80255-0

[7] Gunn, R.S. (1985) Dislocation of the Hamate Bone. Journal Hand Surgery. British, 10, 107-108. http://dx.doi.org/10.1016/S0266-7681(85)80033-4

[8] Zieren, J., Agnes, A. and Mueller, J.M. (2000) Isolated Dislocation of the Hamate Bone, Case Report and Review of the Literature. Archives Orthop Trauma Surgery, 120, 535-537.

[9] Johansson, S. (1926) Ein Fall der Luxation von Os Hamatum. Acta Radiologica, 7, 9-13. http://dx.doi.org/10.3109/00016922609138248

[10] Mathison, G.W. and MacDonald, R.I. (1975) Irreducible Transcapitate fractUre and Dislocation of the Hamate. Report of a Case. Journal of Bone and Joint Surgery. American, 57, 1166-1167.

[11] Matsumoto, T., Tsunoda, M., Yamagushi, S., Koso, K., Matsushita, S., Kurosaka, M. and Yoshiya, S. (2005) Traumatic Dislocation of the Hamate and Pisiform: A Case Report and Review of the Literature. Journal of Orthopaedic Trauma, 19, 282-285. http://dx.doi.org/10.1097/01.bot.0000135839.17363.93 
Scientific Research Publishing (SCIRP) is one of the largest Open Access journal publishers. It is currently publishing more than 200 open access, online, peer-reviewed journals covering a wide range of academic disciplines. SCIRP serves the worldwide academic communities and contributes to the progress and application of science with its publication.

Other selected journals from SCIRP are listed as below. Submit your manuscript to us via either submit@scirp.org or Online Submission Portal.
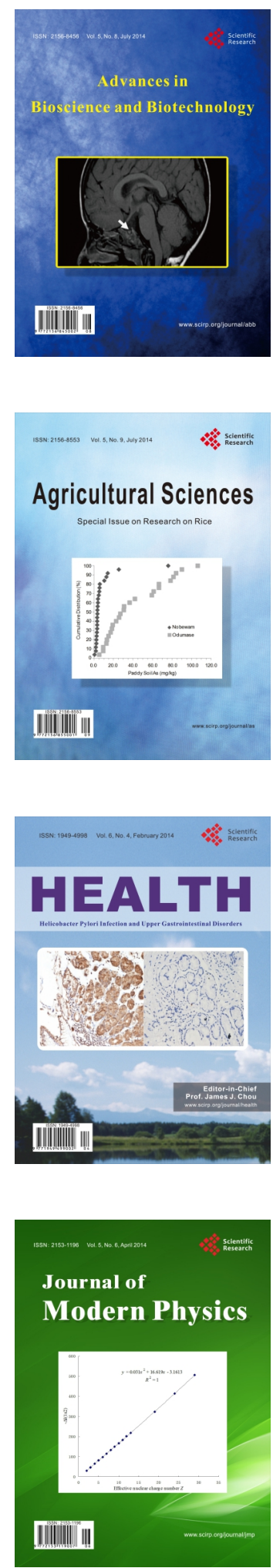
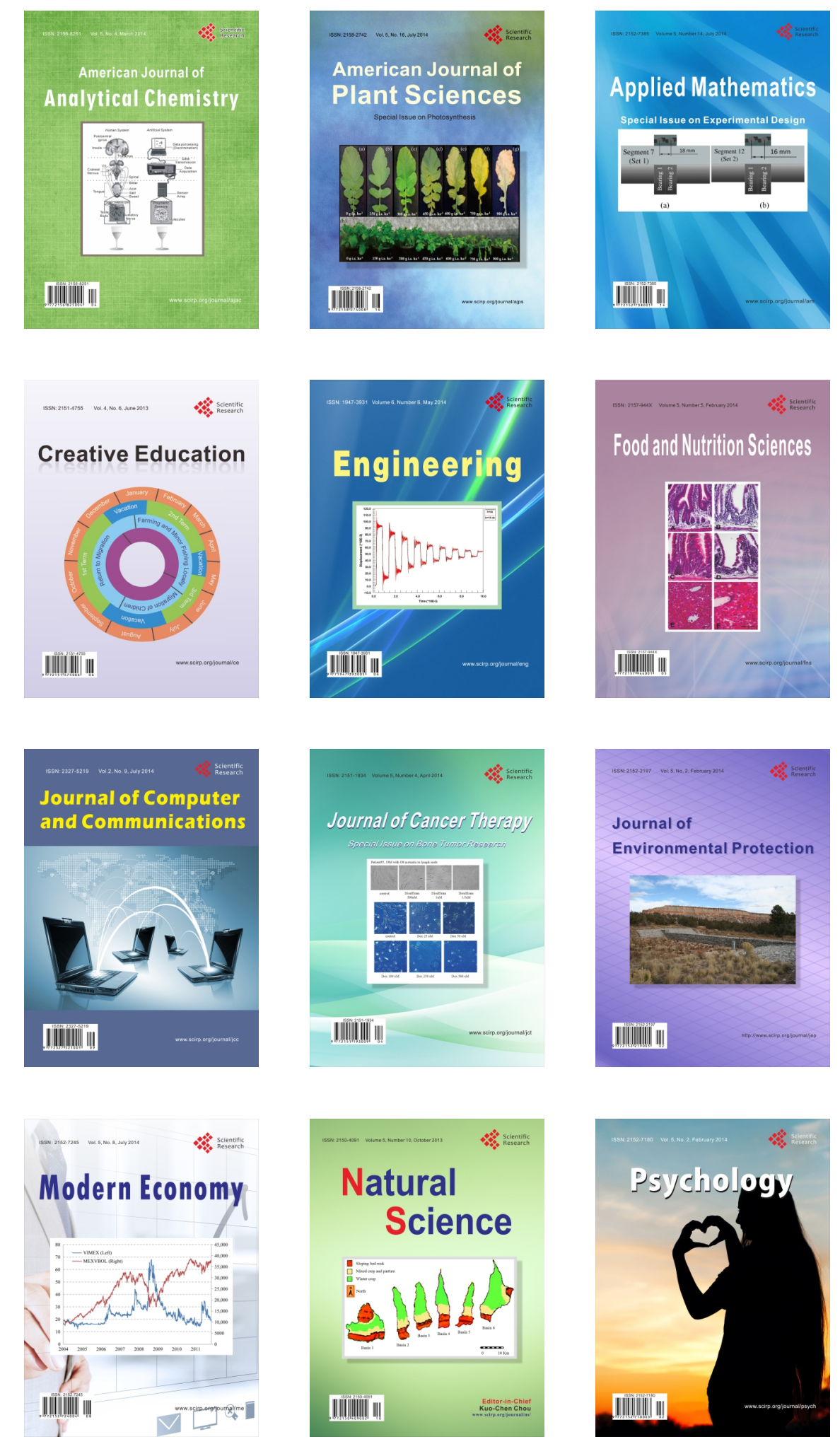